\title{
In Search of the U1 snRNA from Entamoeba histolytica
}

\section{María Saraí Mendoza Figueroa and Jesús Valdés*}

Department of Biochemistry, Centro de Investigaciones y de Estudios Avanzados del I.P.N., Avenida I.P.N. 2508, Colonia San Pedro Zacatenco, México, D.F. 07360, México

Most early branching eukaryotes have few or no intron-interrupted genes. In the almost ten thousand genes of the protozoan parasite Entamoeba histolytica a little less than 2 thousand introns have been reported [1]. From these, just a few have been validated by comparison of the genomic and cDNA sequences and or RT-PCR [2-9]. Strikingly, most of the identified Entamoeba introns possess well-conserved 5' (GUUUGU) and 3' (UAG) splice sites (ss) although the Branch point Sequences (BS) are less conserved or not identifiable at all [7]. Also, the Entamoeba introns share a strong intron mean size bias of 50 nucleotides. Due to their size it has been proposed that the splicing mechanism operates through intron definition [10].

Data mining of amoebic proteins led to infer that Entamoeba sp and their common ancestor as well possess the components of the major spliceosome [11], which might be responsible for the splicing events performed by this parasite, as suggested by their data. Furthermore, the U2, U4, U5 [9] and U6 snRNA [12] have been cloned and identified.

Two pieces of information are still required to approach the problem of snRNP functions in the amoebic spliceosome. The first is the identification of the identification of the U1 snRNA; the second is to gain functional insights of these snRNPs.

We wish to put forward a strategy for the recovery and identification of the Entamoeba U1 snRNA. To this end, it has been customary to perform immunoprecipitation experiments using antibodies targeted to one of the U1 snRNP components assembled therein during its biogenesis, for example U1 70K [13]. This approach has proven to be useful to disclose the snRNA sequence and the snRNP structure, and using in vitro splicing assays it also provided mechanistic insights of the U1 snRNP.

In a recent paper, Shao et al. [14] reported a variation to this approach, allowing not only the precipitation of the U1 snRNP but also evidencing its functional relationships with other spliceosomal components during intron definition in the fission yeast Schizosaccharomyces pombe. They had previously shown that the DExD/H RNA-dependent ATPase Prp5 interacts with both U1 and U2 snRNP during intron definition in [15]. They expressed a tagged Prp5 in the fission yeast, and coimmunoprecipitated the proteins interacting with this splicing factor. This way Shao and coworkers found that SF3b mediates U2 snRNP/ Prp5 recognition as much as Rsd 1 mediates U1A (a component of the U1 snRNP)/Prp5 recognition.

Since all of the aforementioned factors have been annotated in the Entamoeba genome, it is possible that using a similar approach the U1 snRNA could be isolated. Albeit two DExD/H ATPases are readily identified in the Entamoeba databases, no information is available regarding which of them performs the role Prp5 exerts during spliceosome assembly. Therefore, to carry out this approach in two well conserved proteins can be used, SF3b or U2AF65, both of them key factors in U2 snRNP recognition of the 5'ss. In addition, the method itself provides the appropriate co-immunoprecipitation controls, namely the U2 snRNA, and provides insights in U1 snRNP functions.

\section{References}

1. Loftus B, Anderson I, Davies R, Alsmark UC, Samuelson J, et al. (2005) The genome of the protist parasite Entamoeba histolytica. Nature 433: 865-868.

2. Lohia A, Samuelson J (1993) Cloning of the Eh cdc2 gene from Entamoeba histolytica encoding a protein kinase p34cdc2 homologue. Gene 127: 203-207.

3. Plaimauer B, Ortner S, Wiedermann G, Scheiner O, Duchene M (1994) An intron-containing gene coding for a novel 39-kilodalton antigen of Entamoeba histolytica. Mol Biochem Parasitol 66: 181-185.

4. Urban B, Blasig C, Forster B, Hamelmann C, Horstmann RD (1996) Putative serine/threonine protein kinase expressed in complement-resistant forms of Entamoeba histolytica. Mol Biochem Parasitol 80: 171-178.

5. Sanchez-Lopez R, Gama-Castro S, Ramos MA, Merino E, Lizardi PM, et al. (1998) Cloning and expression of the Entamoeba histolytica ERD2 gene. Mol Biochem Parasitol 92: 355-359.

6. Willhoeft U, Hamann L, Tannich E (1999) A DNA sequence corresponding to the gene encoding cysteine proteinase 5 in Entamoeba histolytica is present and positionally conserved but highly degenerated in Entamoeba dispar. Infect Immun 67: 5925-5929.

7. Wilihoeft U, Campos-Gongora E, Touzni S, Bruchhaus I, Tannich E (2001) Introns of Entamoeba histolytica and Entamoeba dispar. Protist 152: 149-156.

8. Marchat LA, Orozco E, Guillen N, Weber C, Lopez-Camarillo C (2008) Putative DEAD and DExH-box RNA helicases families in Entamoeba histolytica. Gene 424: $1-10$.

9. Davis CA, Brown MP, Singh U (2007) Functional characterization of spliceosomal introns and identification of $\mathrm{U} 2, \mathrm{U} 4$, and $\mathrm{U} 5$ snRNAs in the deep-branching eukaryote Entamoeba histolytica. Eukaryot Cell 6: 940-948.

10. McGuire AM, Pearson MD, Neafsey DE, Galagan JE (2008) Cross-kingdom patterns of alternative splicing and splice recognition. Genome Biol 9: R50.

11. Collins L, Penny D (2005) Complex spliceosomal organization ancestral to extant eukaryotes. Mol Biol Evol 22: 1053-1066.

12. Miranda R, Salgado LM, Sanchez-Lopez R, Alagon A, Lizardi PM (1996) Identification and analysis of the u6 small nuclear RNA gene from Entamoeba histolytica. Gene 180: 37-42.

13. Hamm J, Kazmaier M, Mattaj IW (1987) In vitro assembly of U1 snRNPs. EMBO J 6: 3479-3485.

14. Shao W, Kim HS, Cao Y, Xu YZ, Query CC (2012) A U1-U2 snRNP interaction network during intron definition. Mol Cell Biol 32: 470-478.

15. Xu YZ, Newnham CM, Kameoka S, Huang T, Konarska MM, et al. (2004) Prp5 bridges $\mathrm{U} 1$ and $\mathrm{U} 2$ snRNPs and enables stable U2 snRNP association with intron RNA. EMBO J 23: 376-385.

*Corresponding author: Jesús Valdés, Department of Biochemistry, Centro de Investigaciones y de Estudios Avanzados del I.P.N., Avenida I.P.N. 2508, Colonia San Pedro Zacatenco, México, D.F. 07360, México, Tel +52(55) 57473854; E-mail: jvaldes@cinvestav.mx

Received March 14, 2012; Accepted March 15, 2012; Published March 21, 2012

Citation: Mendoza Figueroa MS, Valdés J (2012) In Search of the U1 snRNA from Entamoeba histolytica. J Bacteriol Parasitol 3:e102. doi:10.4172/21559597.1000e102

Copyright: (c) 2012 Mendoza Figueroa MS, et al. This is an open-access article distributed under the terms of the Creative Commons Attribution License, which permits unrestricted use, distribution, and reproduction in any medium, provided the original author and source are credited. 